\title{
Social phobia: diagnosis and epidemiology, neurobiology and pharmacology, comorbidity and treatment
}

N. Brunello, J.A den Boer, L.L Judd, S. Kasper, J.E Kelsey, M. Lader, Y. Lecrubier, J.P Lepine, R.B Lydiard, J. Mendlewicz, S.A Montgomery, G. Racagni, M.B Stein, H.-U Wittchen

\begin{abstract}
Social phobia is a common disorder associated with significant psychosocial impairment, representing a substantial public health problem largely determined by the high prevalence, and the lifelong chronicity. Social phobia starts in early childhood or adolescence and is often comorbid with depression, other anxiety disorders, alcohol and substance abuse or eating disorders. This cascade of comorbidity, usually secondary to social phobia, increases the disability associated with the condition. The possibility that social phobia may be a trigger for later developing comorbid disorders directs attention to the need for early effective treatment as a preventive measure.

The most recent drug class to be investigated for the psychopharmacological treatment of social phobia is the SSRI group for which there is growing support. The other drug classes that have been evaluated are monoamine oxidase inhibitors (MAOIs), benzodiazepines, and beta-blockers. The SSRIs represent a new and attractive therapeutic choice for patients with generalized social phobia. Recently the first, large scale, placebo-controlled study to assess the efficacy of drug treatment in generalized social phobia has been completed with paroxetine. Paroxetine was more effective in reducing the symptoms than placebo and was well tolerated. Many now regard SSRIs as the drugs of choice in social phobia because of their effectiveness and because they avoid the problems of treatment with benzodiazepines or classical MAOIs.
\end{abstract}

\section{Keywords}

- Social phobia;

- Anxiety disorders;

- Comorbidity;

- SSRI;

- Paroxetine 


\section{What is social phobia?}

Social phobia is an anxiety disorder with varying degrees of severity. This condition is characterised by clinically significant anxiety reactions and extreme discomfort occurring in anticipation of or upon exposure to social settings, including performance and test situations. Social phobia can interfere with one's social or career development leaving the patient socially isolated and, in some cases, unable to pursue intimate relationships and career fulfilment.

Related to increasingly stringent and more detailed diagnostic criteria for social phobia over the past two decades, there is some variation in epidemiological findings across studies. The National Comorbidity Survey in the US found social phobia to be the third most common psychiatric disorder, after major depression and alcohol dependence (Kessler et al., 1994). The study of Weiller et al. (1996) also found it to be the third most common disorder in primary care after depression and GAD. Nevertheless, social phobia remains one of the least well recognised and understood mental disorders.

The Diagnostic and Statistical Manual of Mental Disorders, 4th edition (DSM-IV) (American Psychiatric Association, 1994) defines social phobia as 'a marked and persistent fear of one or more social performance situations in which the person is exposed to unfamiliar people or to possible scrutiny by others. The individual fears that he or she will act in a way (or show anxiety symptoms) that will be humiliating or embarrassing'. The fear must be seen as excessive or unreasonable by the patient, lead to avoidance of feared situations or cause anticipatory anxiety, and significantly interfere with the patient's social or occupational life. The fear or avoidance must not be the direct effect of any substance or general medical condition.

The reticence that is characteristic of social phobia inhibits many patients from volunteering relevant information (e.g. to a physician, teacher, etc.). In addition, some patients who have built their lives around avoiding their feared situations may also have trouble recognising and reporting areas of functioning in which they are impaired. In other words, some patients see their functional limitation as 'just the way I am'. For these reasons, it is important to be systematic and comprehensive in evaluating social phobia symptoms and the extent of related impairment. Because of the broad spectrum of disability related to social phobia, many experts feel today that it would be preferable to refer to social phobia with the DSM-IV synonym, 'social anxiety disorder'.

This consensus statement summarizes current knowledge of this disorder and emerging data on its treatment.

\section{Diagnosis and epidemiology}

The first problem in establishing a diagnosis of social phobia is the issue of diagnostic thresholds. Distinguishing social phobia from normal shyness is a quantitative issue related to the level of distress and impairment associated with social fears. Because shyness is usually self-defined, it probably represents a more heterogeneous group than social phobia, including cases that would not meet clinical criteria for the disorder. In a recent telephone survey of a community sample, Stein et al. (1994) examined the effects of different thresholds for determining caseness in persons with social anxiety. Different thresholds led to variations in prevalence from $1.9 \%$ to $18.7 \%$, depending on the stringency of the definitions of distress and impairment (Kessler et al., 1998 and Wittchen et al., 1998).

Social phobia is characterised by the presence of physical, cognitive, and behavioural symptoms. The physical symptoms reported by many persons with social phobia include sweating, shaking, blushing, palpitations, nausea, and diarrhoea. In studies using physiologic measures, patients with social phobia show the increased arousal typical of most anxious subjects on exposure to their feared stimuli (e.g. increased heart rate and blood pressure and decreased habituation of skin conductance responses) (Beidel et al., 1985 and Turner et al., 1986).

At the other end of the severity spectrum, another dilemma that appears frequently in the differential diagnosis is avoidant personality disorder, with which social phobia commonly overlaps. Avoidant personality disorder as defined in the DSM-IV appears to be a more severe form of social phobia, however the diagnosis of avoidant personality disorder can be misleading and has not been supported by recent data and these two diagnostic groups do not appear to differ qualitatively in any substantive way (Schneier, 1995).

By following a series of relatively simple rules, the diagnosis of social phobia, for the most part, 
should be fairly straightforward. The A criterion, or the gateway symptom in the diagnosis of social phobia is marked and persistent fear of social or performance situations in which embarrassment may occur (Table 1).

Table 1

Important clinical features of social phobia: typical fears

\begin{tabular}{ll}
\hline Social & Performance \\
\hline Being introduced to strangers & Speaking in public \\
Meeting people in authority & Writing in front of others \\
Eating or drinking in public places & Acting or playing a musical \\
Participating in small groups & instrument in public \\
Entering a party group & Giving a report to a group \\
Being tested & Expressing disagreement \\
\hline
\end{tabular}

Another diagnostic distinction is made in social phobia by subclassifying social phobia into generalised or the more circumscribed or non-generalised type. In generalised social phobia, which is the most debilitating, the patient fears most social interactions and situations. The circumscribed type of social phobia usually involves fears of public performance or speaking when scrutiny is inevitable.

The most difficult differential diagnostic consideration for the clinician in identifying the patient with social phobia is the potential confusion with agoraphobia with and without panic attacks (and panic disorder). The reason for this confusion is that agoraphobics can experience fear reactions and will also avoid specific social situations. However, the agoraphobic avoidance is based primarily on the fact that the patients fear having a panic attack or fear the loss of control in a crowd or social situation from which the patient may not easily escape. They may also fear a social situation in which exit from this situation is embarrassing, difficult or impossible. Compared to patients with panic disorder, social phobics do not have uncued spontaneous panic attacks, however, their anxiety in social phobia sometimes takes the form of symptoms that resemble panic attacks with a tendency of a higher frequency of blushing, muscle twitching, stammering, and dry mouth, while they are less likely to experience dizziness or respiratory symptoms (Amies et al., 1983, Solyom et al., 1986 and Reich et al., 1988).

A careful history will often allow the physician to distinguish the social phobic by eliciting the core clinical feature (A criterion symptom), that the main concern is fear of scrutiny or humiliation in social situations where scrutiny and evaluation may be present. In general, social phobics do not avoid social situations because they fear having a panic attack or where escape is difficult; their avoidance invariably involves fear of evaluation and scrutiny. A significant number of patients who answer advertisements or are referred to psychiatric clinics with diagnoses of panic disorder have proved, on careful diagnostic examination, to be social phobics (Bisserbe et al., 1996). It is highly probable that clinicians may be under-recognising and under-diagnosing social phobia in their practices (Amies et al., 1983, Liebowitz et al., 1985a and Bisserbe et al., 1996).

All epidemiological studies show that social phobia is among the most frequent disorders encountered in the general population (Schneier et al., 1992a; Wacker et al., 1992 and Magee et al., 1996) or in primary care (Weiller et al., 1996). The prevalence of social phobia has been studied in several epidemiological studies throughout the world in the past decade (Wittchen et al., 1996 and Wittchen et al., 1998). Many of the earliest studies were based on DSM-III criteria assessed with the Diagnostic Interview Schedule (DIS) (Robins et al., 1981a and Robins et al., 1981b). The Epidemiologic Catchment Area (ECA) program found the lifetime (LT) prevalence of social phobia to be 2.8\% (Regier et al., 1990). Similar estimates were obtained in community surveys carried out in Munich (2.5\%) (Wittchen et al., 1992), Edmonton (1.7\%) (Bland et al., 1988), Zurich (3.2\%) (Angst and Dobler-Mikola, 1991), New Zealand (3.9\%) (Wells et al., 1989) and Paris (4.1\%) (Lepine and Lellouch, 1995). These prevalences could be regarded as fairly conservative estimates, as the version of the DIS used in these surveys assessed social fears as part of the simple phobia section, covering only a very limited range of those social fears clinically relevant for the evaluation of social phobics (Davidson et al., 1994, Walker and Stein, 1995, Magee et al., 1996 and Wittchen and Beloch, 1996). 
This underestimation problem was corrected in the successor to the DIS, the World Health Organization's Composite International Diagnostic Interview (CIDI) (World Health Organization, 1990) by developing a social phobia diagnostic module that comprehensively evaluates all the types of social fears specified in DSM-III-R and DSM-IV. Community epidemiologic surveys using the CIDI have obtained considerably higher estimates of social phobia prevalence than earlier studies, including a 13.3\% LT prevalence in the National Comorbidity Survey (Magee et al., 1996) and 16.1\% in Basel, Switzerland (Wacker et al., 1992). Although some part of these higher prevalences than in the earlier DIS surveys could be due to differences in sample composition or field procedures, the much more comprehensive screening questions for social fears has been held responsible for most of the increase (Wittchen and Beloch, 1996). So far no epidemiological data have been published reporting prevalence estimates and describing in more detail specific characteristics, such as what proportion of cases suffer from fairly isolated social phobia (e.g. performance anxiety) as well as more generalized forms, how they differ from each other, and what type of cognitive and behavioral correlates are most frequently observed in early and later stages of this disorder.

At this point prevalence estimates for DSM-IV social phobia are only available from one general population study of 3021 subjects aged 14 to 24 on the basis of the CIDI, indicating somewhat considerably lower rates than DSM-III-R studies (Wittchen et al., 1998). This difference in prevalence estimates is probably due to a higher threshold for severity demanded by the version of the CIDI used in this study rather than by differences between DSM-III-R and DSM-IV criteria. Despite the prevalence differences, there is good agreement with regard to the psychosocial correlates and risk factors associated with social phobia in the earlier DIS studies and more recent CIDI studies. They all agree that rates of social phobia are slightly higher among women than men, are considerably more frequent in younger as compared to older age cohorts, and are significantly associated with lower socioeconomic status (Bourdon et al., 1988, Bourdon, 1993 and Magee et al., 1996). Most studies also report that the majority of social phobics have onset in childhood or adolescence (Burke et al., 1990) and usually go untreated (Burns, 1980 and Schneier et al., 1992a; Ross, 1993 and Magee et al., 1996). Social phobia appears in these surveys to be a risk factor for poor school performance, school dropout, poor work performance, unemployment, and alcohol abuse (Mullaney and Trippet, 1979 and Liebowitz et al., 1985a; Davidson et al., 1993a; Wittchen and Beloch, 1996).

Secondary analysis of a number of these surveys shows, consistent with clinical studies (Liebowitz et al., 1985a), that social phobics have a significantly increased risk (as compared to people with no social phobia) of having other anxiety disorders, major depressive as well as substance use disorders (Merikangas et al., 1996, Lepine and Pelissolo, 1996 and Lecrubier and Weiller, 1997), which seem to occur mostly secondary in time to the development of social phobia. However, the findings on temporality of disorders should be taken cautiously, due to the retrospective assessment strategies used in these studies. From an etiological perspective, several prospective studies in children (Biederman et al., 1990 and Rosenbaum et al., 1992) also suggest on the basis of prospective studies in children, that 'behavioral inhibition' (long latency to approach a stranger in behavioral studies), a fairly well-defined temperamental construct, might be a powerful antecedent for the later development of social phobia and, perhaps, other anxiety disorders.

The clinical course of social phobia can be chronic, however clinical observations suggest considerable variations, thus more research is needed. Patients often enter treatment later in life, frequently reporting suffering from severe symptoms for many years before seeking treatment. Thus, the combination of a very early onset, together with a chronic lifetime course indicates that social phobia is often associated with many decades of social impairment and disability.

Social phobics have been reported to have significantly lower levels of educational achievement in terms of years of school completed. More than half of the social phobics who have been studied were sufficiently impaired in their educational achievement that they were unable to complete high school. Even more striking, is that social phobics are often in the lowest two quartiles of socioeconomic status in the society, with over $70 \%$ of social phobics falling in the lower half of the population in terms of socioeconomic achievement. Schneier et al. (1994) have reported that $22.3 \%$ of their sample of US patients with pure social phobia are currently on welfare, implying that they are unable to work or hold a job consistently. Because of the severe impediments associated with social phobia in terms of human interaction and social discourse, there is evidence that over half of all social phobics are single, divorced or separated. In the area of non-romantic relationships, shyness has been reported to correlate with low sociability and loneliness (Anderson and Harvey, 1988). More than $90 \%$ of a group of 
patients with social phobia reported that their anxiety interfered significantly with occupational functioning, and 85\% reported interference with academic functioning (Beidel et al., 1985). In a prospective study lasting over 30 years that compared outcome in shy versus non-shy boys, shy boys tended to enter a steady career later, hold lower status jobs, and have less occupational stability than non-shy boys (Caspi et al., 1988). Similarly, shy girls were less likely to have entered the work force or to have re-entered it after childbirth than were non-shy girls (Phillips and Bruch, 1988). Similar findings have been reported in Germany (Wittchen et al., 1998) and in France (Weiller et al., 1996).

Schneier et al. (1994) developed two new scales to estimate disability among social phobics: these are the Disability Profile (DP), a clinical rating instrument, and the Liebowitz Self-Rated Disability Scale (LSRDS). These scales were developed to augment the instruments available to assess disability in social phobia and potentially other psychiatric disorders. In 1993, Schneier et al. administered these scales to 32 patients with social phobia and 14 normal control subjects. They reported, consistent with other reports of social disability in social phobia, that social phobic patients reported moderate to severe impairment during their lives due to social anxiety and avoidance in education, employment, family relationships, marriage/romantic relationships, friendships/social network and other interests. Although the sample of patients is small, these results confirm other reports involving larger samples.

Those investigations which focused upon the impact of social phobia on the domains of everyday functioning, provide a confluence of strong empirical evidence, that social phobia is associated with significant disability and dysfunction in those afflicted. This, combined with the high prevalence and the chronic nature of social phobia, indicate it is a disorder of major public health significance.

\section{Comorbidity}

Social phobia is often associated with other psychiatric disorders. One study found that $59 \%$ of people with the disorder also had simple phobias (such as fear of heights or spiders), $49 \%$ had panic disorder with agoraphobia, 19\% were alcohol abusers, and 17\% suffered from major depression. About 10 to $20 \%$ of patients in clinics for anxiety disorders suffer from social phobia; it is the most common secondary diagnosis among patients with another anxiety disorder. In clinical samples, comorbidity is extensive with major depression (40-85\% current, 50-90\% lifetime), dysthymia (20$50 \%$ ), other anxiety disorders (panic disorder, GAD, OCD), substance use disorders (alcohol abuse/dependence) especially in men. In epidemiologic samples, comorbidity is somewhat less extensive but patterns of comorbidity are very similar, e.g. major depression, panic disorder, GAD.

The symptoms overlap with those of panic disorder, and sometimes they are difficult to distinguish, as in cases where a person has a panic attack while giving a speech and afterward dreads all public speaking. The difference is that people with panic disorder do not fear scrutiny itself but the physical sensations associated with a feeling of being endangered and trapped.

Comorbidity of anxiety and mood disorders is common, and social phobia is no exception. Given the high degree of impairment associated with social phobia, especially in the area of interpersonal relationships, it is not surprising that many patients with social phobia develop secondary depressive symptoms. Alternatively, social phobia and depression may arise from a common vulnerability. 'Atypical depression', which is characterised by hypersensitivity to rejection or criticism, has been noted to bear similarity to social phobia (Liebowitz et al., 1985a) and both appear to respond preferentially to monoamine oxidase inhibitors (MAOIs) as opposed to tricyclic antidepressants. As with alcoholism, the onset of social phobia usually precedes the onset of the mood disorder (Sanderson et al., 1990 and Schneier et al., 1992a). Additionally, suicidal ideation has been found to occur frequently among patients with social phobia, and the frequency of suicidal attempts may be higher than otherwise expected (Schneier et al., 1992a; Davidson et al., 1993a; Lepine and Lellouch, 1995).

Major depression is often associated with social phobia, and family members of patients with social phobia have a high rate of depression. In one study people with both social phobia and panic disorder had a 95\% risk of developing major depression. The order of cause and effect is not clear. Depression might lead to social withdrawal, or social withdrawal to depression; and the disorders might have common causes in heredity and upbringing. Depressed patients usually say that social phobia came first, but they are not necessarily right, since memories distorted by sadness and hopelessness may magnify normal reticence into a disabling disorder. For patients with a current diagnosis of social phobia, the co-occurrence of depressive episodes is frequent and extremely 
disabling. Both symptomatic severity, social disability and suicide rates show that the comorbid condition is much more severe than 'pure' social phobia (Lecrubier and Weiller, 1997)

People with social phobias often use alcohol as self-medication. Alcoholics have nine times the rate of social phobia; one study found that about $15 \%$ of socially phobic men and women had had an alcohol problem at some time in their lives. Usually they must solve that problem before they can benefit from treatment for social phobia. If they have used alcohol (or an addictive illicit drug) long enough, the original symptoms of social phobia are obscured, and anxiety that reappears when they stop the drinking or drug use may be mistaken for withdrawal symptoms. Unfortunately, Alcoholics Anonymous and similar self-help groups for addicts are often ineffective for people with social phobias, because members are required to talk about themselves before an audience.

\section{Neurobiology of social phobia}

Despite social phobia being a common psychiatric disorder (Kessler et al., 1994), the understanding of its pathophysiology is less than that for other disorders. Clues to the biology of this disorder come from one of several approaches; response to drug treatment, measurement of resting hormonal or neurotransmitter indices, pharmacological or behavioural challenges, and neuro-imaging studies, both structural and functional.

\subsection{Resting measurements}

One strategy to explore the biology of social phobia is to determine hormonal levels, receptor concentrations, reuptake sites or other markers in the periphery which may reflect differences in the central nervous system (CNS) and provide insight into a biological mechanism. Contrasts between patients with social phobia and normal controls, or other patient populations, would presumably reflect on tonic differences independent of the presence or absence of a phobic stimulus.

A number of studies have examined the hypothalamic-pituitary-adrenal (Potts et al., 1991) or hypothalamic-thyroid axis (Tancer et al., 1990) and no significant differences have been detected among patients with social phobia and normal controls.

No differences have been reported in neuropeptide Y levels (Stein et al., 1996b) and serum interleukin-2 or soluble interleukin-2 receptors (Rapaport and Stein, 1994) in patients with social phobia compared to normal controls. Platelet 5HT2 receptor density is the same between patients with social phobia and normal controls (Chaterjee et al., 1997). There are also no differences in serotonin transporter densities in the platelets of patients with social phobia compared to those with panic disorder or normal controls using ${ }^{3} \mathrm{H}$-paroxetine binding (Stein et al., 1995).

Brain imaging studies of patients with social phobia have been performed in the resting state. Potts et al. (1994) examined magnetic resonance imaging (MRI) scans of brains in patients with social phobia compared to age- and sex-matched controls. No differences were found between the two groups in comparison of total cerebral, caudate, putamen or thalamic volumes. The patients with social phobia did have an age-related reduction in putamen volume that was greater than was observed for the normal control group, though the significance of this is not known.

Tiihonen et al. (1997) have examined dopamine reuptake sites using a ${ }^{123}$ I-labelled cocaine analogue and single photon emission computed tomography (SPECT) reporting that social phobics demonstrated lower dopamine reuptake densities in the striatal region, compared to normal controls.

Except for the differences in striatal dopamine reuptake sites using SPECT (Tiihonen et al., 1997), the measurement of differences between patients with social phobia and normal controls during a resting state has not been informative of positive differences. Since social phobia is a disorder that is symptomatic in response to the phobic stimulus, or thinking about the phobic stimulus, it is possible that challenge studies or dynamic measures may be more informative. 


\subsection{Dynamic measurements}

Challenge studies are often used as a probe of endocrine or neurotransmitter functioning. These studies typically involve the administration of a chemical or a manoeuvre that may be anxiogenic in another anxiety disorder. Many of these challenges have been with compounds that elicit panic attacks in patients with panic disorder.

Liebowitz et al. (1985b) demonstrated that infusion of sodium lactate produced panic attacks in 10 of 20 patients with panic disorder but only one of 15 in patients with social phobia. Inhalation of 35\% $\mathrm{CO}_{2}$ (Papp et al., 1993) induced a panic response in 13/18 panic disorder patients, 6/20 social phobia patients and 1/23 control subjects. Infusion of epinephrine produced observable anxiety in only 1/11 patients with social phobia (Papp et al., 1988). Social phobics, like patients with panic disorder, have a higher incidence of panic attacks following inhalation of $35 \% \mathrm{CO}_{2}$ (Caldirola et al., 1997) or infusion of intravenous pentagastrin (Van Vliet et al., 1997a and McCann et al., 1997), but these findings are not specific to social phobia. When comparing 19, 11 and 19 patients with social phobia, panic disorder, or healthy controls, respectively, panic attacks were produced in $47 \%$ of social phobics, $64 \%$ of patients with panic disorder, and $11 \%$ of the normal controls (McCann et al., 1997).

A multi-probe study of serotonergic, noradrenergic or dopaminergic functioning in patients with social phobia, compared to normal controls, was reported by Tancer et al. (1994). In this study, a double-blind, placebo-controlled challenge was administered using fenfluramine (serotonergic probe), levo-DOPA (dopaminergic probe) or clonidine (noradrenergic probe). Social phobics demonstrated an augmented cortisol response to fenfluramine compared to normal controls. There were no differences between the patients with social phobia and the normal controls in response to the prolactin response to fenfluramine, GH or norepinephrine response to clonidine (oral administration), or the prolactin or eye-blink responses to levo-DOPA.

Social phobics appear to produce higher levels of norepinephrine in response to postural changes than do either normal controls or patients with panic disorder but the percentage of change is equal since social phobics had higher baseline levels of circulating norepinephrine (Stein et al., 1992). This finding obtained in a laboratory setting is not surprising given the nature of the illness.

To date however, there have been no published reports of pharmacological studies that specifically elicit symptoms of social phobia.

Our understanding of the biology of social phobia has advanced significantly over the past few years. Unfortunately, much of what has been discovered relates to systems in which social phobia does not differ from other anxiety disorders, or the responses of normal controls. Responses to medications has suggested involvement of the serotonergic and GABAergic systems, and perhaps the noradrenergic pathways as well. It is not clear though if it is these neurotransmitter systems that are dysregulated, or, if these are the neurotransmitter systems that are most amenable to manipulation with our currently available pharmacological agents. It is expected that measurements in a more dynamic setting, such as during exposure to phobic stimuli, should broaden our understanding of this common, but serious disorder.

\section{Pharmacological and cognitive treatment}

Social phobia was once thought of as a personality trait, but the observation that serotonergic agents appear to be effective for its treatment (Lydiard, 1998) suggests that patients may have abnormal serotonergic neurotransmission within the central nervous system (Tancer et al., 1994).

The first step in pharmacotherapy of SP is the treatment of social phobia and adequate treatment of depression or other comorbid conditions is also an important consideration. Secondly, since social phobia is a chronic condition, choosing a treatment that can be well tolerated over long periods is an important aspect of enhancing compliance. The ideal outcome of achieving medication-free status may not be a reasonable goal for all patients and should certainly not be pursued at the expense of the patient's well-being.

From a clinical perspective, the decision to treat anxiety disorders with medication involves an interplay between the experience and orientation of the clinician, the expectations and wishes of the patient, and the severity of the disorder affecting the patient. Severe, generalised social phobia is a serious disorder that merits early treatment intervention — including pharmacological therapy — to prevent or reverse the significant disability which accompanies untreated social phobia. Social phobia 
commonly develops during the teenage years and may result in psychosocial development becoming arrested at this stage. After a response to treatment, a long period of 'catching-up' may be necessary as the gains are consolidated after the resumption of psychosocial development. Chronic treatment is therefore necessary in many cases and so it is essential that drug treatment is well tolerated. The monoamine oxidase inhibitors (MAOIs), benzodiazepines and, more recently, the selective serotonin reuptake inhibitors (SSRIs) have all shown promise as treatments for social phobia in terms of efficacy, but these different classes of drugs show important differences in tolerability, such as sedation, insomnia, sexual dysfunction, dependence liability and drug-drug interactions.

\subsection{Monoamine oxidase inhibitors}

Non-selective monoamine oxidase inhibitors (MAOIs), both irreversible and reversible, inhibit the metabolism of 5HT, NE and DA. The irreversible MAOI, phenelzine, is effective in the treatment of social phobia (Liebowitz et al., 1992 and Versiani et al., 1992). Tranylcypromine (Versiani et al., 1988) has shown efficacy for the treatment of social phobia in an open label trial. Phenelzine is the most extensively studied MAOI in the treatment of social phobia and its efficacy is well established (e.g. Gelertner et al., 1991, Liebowitz et al., 1992 and Versiani et al., 1992). There are less data on tranylcypromine but it might be expected to be effective in this condition. However, these agents require a restricted diet to avoid severe hypertensive crises after the ingestion of foods containing tyramine, and tolerability may be a problem over both the short and long term. Other adverse effects include insomnia, sexual dysfunction, postural hypotension, and weight gain. The reversible and selective MAOIs brofaromine (Van Vliet et al., 1992, Fahlen et al., 1995, Slaap et al., 1996 and Lott et al., 1997) and moclobemide (Versiani et al., 1992 and Versiani et al., 1996) have also demonstrated superiority to placebo in some, but not all (Noyes et al., 1997 and Schneier et al., 1998), double-blind studies of social phobia. At standard dosage moclobemide does not require dietary restriction, but at considerably higher doses, required by some patients, selectivity is lost.

\subsection{Beta blockers}

These agents have performed poorly in controlled clinical trials of patients who mainly suffered from generalised subtype of social phobia (Liebowitz et al., 1992). However, anecdotal experience and controlled trials in anxious performers, suggest that they are effective for circumscribed symptoms of performance anxiety, especially if physiological tremor suppression is an advantage (e.g. violinist) (Bailly, 1996). Beta blockers have the advantages of as-needed use and of rarely impairing concentration or coordination and not inducing dependence. A non-selective beta blocker (affecting both the beta1-adrenergic receptors in the heart and the beta2-adrenergic receptors that mediate tremor), such as propranolol or nadolol, may in theory be more effective than a beta blocker selective for beta1-adrenergic receptors, such as atenolol or metoprolol, although this remains to be empirically tested (Schneier et al., 1992c). Before starting therapy with beta blockers, an electrocardiogram is often advisable to rule out the presence of atrioventricular (AV) block. Patients may then be instructed to try a test dose at home, both to ensure that the degree of beta blockade is sufficient and that untoward side effects will not develop during the performance. Beta blockers are contraindicated in patients with asthma and for use during athletic performance because beta blockers can diminish peak performances during activities that depend on high cardiac output. However it should be underlined that generalized social phobia, as currently defined by DSM-IV or ICD10, is not an indication for beta-blockers.

\subsection{Benzodiazepines and other anxiolytics}

Both alprazolam and clonazepam have improved some patients in a number of open studies in social phobia (Lydiard et al., 1988, Reich et al., 1989, Munjack et al., 1990, Ontiveros and Fontaine, 1990 and Reiter et al., 1990). A placebo-controlled trial of clonazepam achieved response rates approaching 80\%, compared with 20-25\% in placebo-treated patients (Davidson et al., 1993b).

Benzodiazepines can be effective symptom-suppressants for social phobia, but the relapse rates may be high (though it should be pointed out that controlled data are lacking) after treatment is 
discontinued. Limitations for these agents are the lack of efficacy in depression, legal restriction for chronic use in some countries and their contraindication in patients who abuse alcohol or illicit drugs. In addition, treatment with benzodiazepines can be associated with the development of dependence. Since social phobia generally requires long-term therapy the role of benzodiazepines as a monotherapy for social phobia remains controversial. Buspirone, a non-benzodiazepine anxiolytic, has been used in social phobia (Clark and Agras, 1991 and Schneier et al., 1993). The results of double-blind trials do not support its usefulness (Van Vliet et al., 1997b).

\subsection{Serotonin selective reuptake inhibitors}

Initial data from trials performed to examine the efficacy of the SSRIs have provided some evidence of efficacy, although comparisons between them are complicated by variations in study design and protocol. Efficacy in social phobia has been described in case reports for citalopram (Lepola et al., 1994 and Bouwer and Stein, 1998), open trials for fluoxetine (Schneier et al., 1992b; Van Ameringen et al., 1993) and double blind placebo controlled studies for fluvoxamine (Van Vliet et al., 1994), paroxetine (Stein et al., 1996a), sertraline (Katzelnick et al., 1995).

The results of these preliminary trials were encouraging but patient numbers were small and more evidence from larger trials was required. The first, large scale, placebo-controlled study to assess the efficacy of paroxetine in the most severe form of social phobia, generalised social phobia, has recently been completed in 183 patients meeting DSM-IV criteria for generalised social phobia. The main outcome measures were the mean change from baseline of the LSAS (Liebowitz Social Anxiety Scale) and a rating of 'very much improved' or 'much improved' (i.e. a score of 1 or 2) on the CGI (Clinical Global impression). Baseline assessments were comparable in the two groups. For both main outcome variables paroxetine was significantly more effective than placebo (Stein et al., 1998).

The responses to medications in the treatment of social phobia suggest some role for the serotonergic and GABAergic systems, indicated by responses to SSRIs and benzodiazepines, respectively. The role of noradrenergic systems alone is less clear. All of the MAOIs, reversible and irreversible, inhibit not only 5HT, but also NE and DA metabolism. There is no clinical data published on reboxetine in social phobia but evaluating the efficacy of treating social phobia with reboxetine, a selective NE reuptake inhibitor, might help to clarify the role of the noradrenergic system. In the only published report on the efficacy of venlafaxine, a dual 5HT/NE reuptake inhibitor, the mean dose was $\sim 150 \mathrm{mg} /$ day, a dose at which blood-pressure data suggests noradrenergic activity is present (Kelsey, 1995). Patients included in this open-label trial had failed to respond or tolerate treatment with SSRIs and had a marked improvement on venlafaxine.

\subsection{Cognitive-behavioural treatments}

Significant advances in the non-pharmacological treatment of social phobia have been made and scientifically validated. Several different cognitive behavioural treatment models have been developed, and it is not yet clear whether anyone is superior to the others (Lydiard and Falsetti, 1995). Substantial evidence for the effectiveness of various types of CBT in social phobia has accrued (Heimberg et al., 1998). It currently appears that CBT and pharmacotherapy are about equally effective in uncomplicated generalised and nongeneralised social phobic samples, although nongeneralised patients have higher remission rates with treatment (Lydiard and Falsetti, 1995). Most clinicians believe that combined CBT and medication treatment may be optimal treatment for many patients. Controlled studies designed to test this clinical impression are currently underway.

\subsection{Long-term treatment}

Comparisons of drug and non-drug treatments are sparse and often vitiated by inadequate control of self-exposure in the drug-treated groups. Data concerning optimal strategies in a combined approach are almost non-existent as elaborate treatment designs are needed to explore this issue.

Efficacy has been established in acute treatment in studies of relatively short duration. Social phobia is however a long term illness and we need to know whether treatment in the short term produces a persisting effect or whether long term or repeated treatment is required to maintain 
response. Few studies have followed patients up over a longer period to establish long term efficacy. However some evidence suggests that the gains made during short term treatment may increase and be maintained subsequently.

The need for long term treatment is indicated by a follow up of the patients included in the early short-term study of phenelzine and of moclobemide compared with placebo (Nutt and Montgomery, 1996). Long term follow up of responders in this study recorded significantly more relapses on placebo than with moclobemide or phenelzine. When responders were randomised to continue active drug or placebo, relapse occurred within 2 months in between one half and one third of patients on placebo but not in those on active medication demonstrating that these drugs were associated with long term efficacy. The deterioration in response after randomisation at 16 weeks was gradual and persistent and therefore unlikely to have been a reflection of drug withdrawal effects (Versiani et al., 1992).

Further evidence of long term efficacy has been obtained from the 4-year follow up of social phobia patients treated with moclobemide. In this study 93 patients with severe social phobia and various degrees of comorbid psychiatric disorder were treated openly with moclobemide for 2 months. Of these 59 continued treatment for 2 years and then entered a no treatment phase of at least a month. In the no treatment phase only seven patients remained well and the remainder deteriorated. When treatment was reintroduced for a further period of 2 years, patients again improved and there was a gradual decrease in severity scores. When the drug was discontinued or doses were reduced at the end of that period resurgence of symptoms was again seen in many patients (Versiani et al., 1997).

These results suggest that even if some of the gains are maintained, for full improvement the medication needs to be continued.

Another insight from this study was the poor outcome of patients with comorbid alcohol abuse. These patients generally did not improve during medication treatment, nor did they respond when switched at the end of the study to psychotherapy. This result underlines the need for early treatment to prevent the development of comorbid conditions.

Long-term treatment data are beginning to accrue and include both evaluations of continuing efficacy in short-term responders and prevention-of-relapse paradigms. As social phobia is a life-long disorder with major psychosocial implications, further long-term studies and follow-up studies are essential.

Meanwhile, guidelines have to rely on consensus opinion based on clinical practice. Most experts agree that milder forms of social phobia, or those restricted to particular situations (e.g. public speaking only) may respond well to nonpharmacologic interventions or to p.r.n. beta-blockers or p.r.n. benzodiazepines. For more severe cases, including patients who have the generalised subtype, p.r.n. medications are not indicated, but regular medication use is. It is not yet possible to specify which patients will respond best to regular pharmacotherapy, to cognitive-behavioural therapy, or to both. Given the relative availability and accessibility of these various treatments, however, it is likely that many patients will benefit from regular pharmacotherapy.

In this regard, the use of MAOIs — in particular phenelzine — is well-established as the 'gold standard' in the treatment of social phobia. However, because of dietary restrictions and other sideeffects frequently associated with their use (e.g. postural side-effects, weight gain, sexual side-effects), MAOIs are no longer considered by most experts to be a 'first-line' treatment for social phobia. Rather, given the strong and growing evidence for their utility, most expert clinicians now consider the SSRIs to be the pharmacological treatment-of-choice for this condition. Among the SSRIs, paroxetine has been the best-studied (e.g. Stein et al., 1998), though it is likely that other SSRIs will eventually display similar efficacy. Benzodiazepines may have a role to play, either as an adjunctive agent or for patients who are refractory to other treatments. Further research is needed on many aspects of the management of patients suffering from social phobia but major advances have been made in the last few years and considerable optimism is justified.

\section{Acknowledgements}

This paper has been produced by a group of experts supported by an unrestricted educational grant from SmithKline Beecham. 


\section{References}

American Psychiatric Association, 1994, American Psychiatric Association, Diagnostic and Statistical Manual of Mental Disorders (4th ed) American Psychiatric Press, Washington, DC (1994), pp. 416-417

Amies et al., 1983, P.L. Amies, M.G. Gelder, P.M. Shaw, Social phobia: a comparative clinical study, Br. J. Psychiatry, 142 (1983), pp. 174-179

Anderson and Harvey, 1988, C.A. Anderson, R.J. Harvey, Discriminating between problems in living: an examination of measures of depression, loneliness, shyness and social anxiety, J. Soc. Clin. Psychol., 6 (1988), pp. 482-491

Angst and Dobler-Mikola, 1991, J. Angst, A. Dobler-Mikola, The Zurich study — V. Anxiety and phobia in young adults, Eur. Arch. Psychiatry Neurol. Sci., 234 (1991), pp. 408-418

Bailly, 1996, D. Bailly, The role of beta-adrenoceptor blockers in the treatment of psychiatric disorders, CNS Drugs, 5 (2) (1996), pp. 115-136

Beidel et al., 1985, D.C. Beidel, S.M. Turner, C.V. Dancu, Physiological, cognitive, and behavioral aspects of social anxiety, Behav. Res. Ther., 23 (1985), pp. 109-117

Biederman et al., 1990, J. Biederman, J.F. Rosenbaum, D.R. Hirschfeld, Psychiatric correlates of behavioral inhibition in young children of parents with and without psychiatric disorders, Arch. Gen. Psychiatry, 47 (1990), pp. 21-26

Bisserbe et al., 1996, J.C. Bisserbe, E. Weiller, P. Boyer, J.P. Lepine, Y. Lecrubier, Social phobia in primary care: level of recognition and drug use, Int. Clin. Psychopharmacol., 11 (Suppl. 3) (1996), pp. 25-28

Bland et al., 1988, R.C. Bland, H. Orn, S.C. Newman, Lifetime prevalence of psychiatric disorders in Edmonton, Acta Psychiatr. Scand., 77 (Suppl. 338) (1988), pp. 24-32

Bourdon et al., 1988, K.H. Bourdon, J.H. Boyd, D.S. Rae, B.J. Burns, J.W. Thompson, B.Z. Locke, Gender differences in phobias: results of the ECA community survey, J. Anxiety Disord., 2 (1988), pp. 227-241

Bourdon, 1993, K.H. Bourdon, Social phobia: an overview of treatment strategies, J. Clin. Psychiatry, 54 (1993), pp. 165-171,

Bouwer and Stein, 1998, C. Bouwer, D.J. Stein, Use of the selective serotonin reuptake inhibitor citalopram in the treatment of generalized social phobia, J. Affect. Disord., 49 (1998), pp. 79-82

Burke et al., 1990, K.C. Burke, J.D. Burke, D.A. Regier, D.S. Rae, Age at onset of selected mental disorders in five community populations, Arch. Gen. Psychiatry, 47 (1990), pp. 511-518

Burns, 1980, L.E. Burns, The epidemiology of fears and phobias in general practice, J. Intern. Med. Res., 8 (Suppl. 3) (1980), pp. 1-8

Caldirola et al., 1997, D. Caldirola, G. Perna, C. Arancio, A. Bertani, L. Bellodi, The 35\% CO2 challenge test in patients with social phobia, Psychiatry Res., 71 (1997), pp. 41-48

Caspi et al., 1988, A. Caspi, G.H. Elder, D.J. Bem, Moving away from the world: life-course patterns of shy children, Dev. Psychol., 24 (1988), pp. 824-831, View Record in Scopus

Chaterjee et al., 1997, S. Chaterjee, T.A. Sunitha, A. Velayudhan, S. Khanna, An investigation into the psychobiology of social phobia: personality domains and serotonergic function, Acta Psychiatr. Scand., 95 (1997), pp. 544-550

Clark and Agras, 1991, D.B. Clark, W.S. Agras, The assessment and treatment of performance anxiety in musicians, Am. J. Psychiatry, 148 (1991), pp. 598-605 
Davidson et al., 1993a, J.R.T. Davidson, D.L. Hughes, L.K. George, The epidemiology of social phobia: findings from the Duke Epidemiological Catchment Area Study, Psychol. Med., 23 (1993), pp. 709-718

Davidson et al., 1993b, J.R.T. Davidson, N.L.S. Potts, E.A. Richichi, R. Krishnan, S.M. Ford, R. Smith, W.H. Wilson, Treatment of social phobia with clonazepam and placebo, J. Clin. Psychopharmacol., 13 (1993), pp. 423-428

Davidson et al., 1994, J.R.T. Davidson, D.L. Hughes, L.K. George, The boundary of social phobia: exploring the threshold, Arch. Gen. Psychiatry, 51 (1994), pp. 975-983

Fahlen et al., 1995, T. Fahlen, H.L. Nilsson, K. Borg, M. Humble, U. Pauli, Social phobia: the clinical efficacy and tolerability of the monoamine oxidase-A and serotonin uptake inhibitor brofaromine. A double-blind placebo-controlled study, Acta Psychiatr. Scand., 92 (1995), pp. 351-358

Gelertner et al., 1991, C.S. Gelertner, T.W. Uhde, P. Cimbolic, D.B. Arnkoff, B.J. Vittone, M.E. Tancer, J.J. Bartko, Cognitive-behavioural and pharmacological treatments of social phobia: a controlled study, Arch. Gen. Psychiatry, 48 (1991), pp. 938-945

Heimberg et al., 1998, R.G. Heimberg, M.R. Liebowitz, D.A. Hope, F.R. Schneier, C.S. Holt, L.A. Welkowitz, H.R. Juster, R. Campeas, M.A. Bruch, M. Cloitre, B. Fallon, D.F. Klein, Cognitive behavioral group therapy vs. phenelzine therapy for social phobia 12-week outcome, Arch. Gen. Psychiatry, 55 (1998), pp. 1133-1141

Katzelnick et al., 1995, D.J. Katzelnick, K.A. Kobak, J.H. Greist, J.W. Jefferson, J.M. Mantle, R.C. Serlin, Sertraline for social phobia: a double-blind, placebo-controlled crossover study, J. Psychiatry, 152 (9) (1995), pp. 1368-1371

Kelsey, 1995, J.E. Kelsey, Venlafaxine in social phobia, Psychopharmacol. Bull., 31 (1995), pp. 767-771

Kessler et al., 1994, R.C. Kessler, K.A. McGonagle, S. Zhao, C.B. Nelson, M. Hughes, S. Eshleman, H.-U. Wittchen, K.S. Kendler, Lifetime and 12-month prevalence of DSM-III-R psychiatric disorders in the United States; results from the National Comorbidity Survey, Arch. Gen. Psychiatry, 51 (1994), pp. 8-19

Kessler et al., 1998, R.C. Kessler, M.B. Stein, P. Berglund, Social phobia subtypes in the National Comorbidity Survey, Am. J. Psychiatry, 155 (5) (1998), pp. 613-619

Lecrubier and Weiller, 1997, Y. Lecrubier, E. Weiller, Comorbidities in social phobia, Int. Clin. Psychopharmacol., 12 (Suppl. 6) (1997), pp. S17-S21

Lepine and Lellouch, 1995, J.P. Lepine, J. Lellouch, Classification and epidemiology of social phobia, Eur. Arch. Psychiatry, 244 (1995), pp. 290-296

Lepine and Pelissolo, 1996, J.P. Lepine, A. Pelissolo, Comorbidity and social phobia: clinical and epidemiological issues, Int. Clin. Psychopharmacol., 11 (Suppl. 3) (1996), pp. 35-41

Lepola et al., 1994, U. Lepola, H. Koponen, E. Leinonen, Citalopram in the treatment of social phobia: a report of three cases, Pharmacopsychiatry, 27 (1994), pp. 186-188

Liebowitz et al., 1985a, M.R. Liebowitz, J.M. Gorman, A.J. Fyer, D.F. Klein, Social phobia: review of a neglected anxiety disorder, Arch. Gen. Psychiatry, 42 (1985), pp. 729-736

Liebowitz et al., 1985b, M.R. Liebowitz, A.J. Fyer, J.M. Gorman et al., Specificity of lactate infusions in social phobia versus panic disorders, Am. J. Psychiatry, 142 (8) (1985), pp. 947-950

Liebowitz et al., 1992, M.R. Liebowitz, F. Schneier, R. Campeas, J. Hollander, A. Fyer, J. Gorman, L. Papp, S. Davies, R. Gully, D.F. Klein, Phenelzine vs. atenolol in social phobia. A placebo-controlled comparison, Arch. Gen. Psychiatry, 49 (1992), pp. 290-300 
Lott et al., 1997, M. Lott, J.H. Greist, J.W. Jefferson, K.A. Kobak, D.J. Katzelnick, R.J. Katz, S.C. Schaettle, Brofaromine for social phobia: a multicenter, placebo-controlled, double-blind study, J. Clin. Psychopharmacol., 17 (1997), pp. 255-260

Lydiard et al., 1988, R.B. Lydiard, M.T. Laraia, E.F. Howell, J.C. Ballenger, Alprazolam in the treatment of social phobia J. Clin. Psychiatry, 49 (1988), pp. 17-19

Lydiard and Falsetti, 1995, R.B. Lydiard, S.A. Falsetti, Treatment options for social phobia, Psychiatr. Ann., 25 (1995), pp. 570-576

Lydiard, 1998, R.B. Lydiard, The role of drug therapy in social phobia, J. Affect. Disord., 50 (Suppl. 1) (1998), pp. S35-39

Magee et al., 1996, W.J. Magee, W.W. Eaton, H.-U. Wittchen, K.A. McGonagle, R.C. Kessler, Agoraphobia, simple phobia, and social phobia in the National Comorbidity Survey, Arch. Gen. Psychiatry, 53 (1996), pp. 159-168

McCann et al., 1997, U.D. McCann, S.O. Slate, M. Geraci, D. Roscow-Terrill, T.W. Uhde, A comparison of the effects of intravenous pentagastrin on patients with social phobia, panic disorder and healthy controls, Neuropsychopharmacology, 16 (1997), pp. 229-237

Merikangas et al., 1996, K. Merikangas, J. Angst, W. Eaton, G. Canino, M. Rubio-Stipec, H. Wacker, H.-U. Wittchen, L. Andrade, C.A. Essau, H. Kraemer, L. Robins, D. Kupfer, Comorbidity and boundaries of affective disorders with anxiety disorders and substance abuse: results of an international task force, Br. J. Psychiatry, 168 (Suppl. 30) (1996), pp. 49-58

Mullaney and Trippet, 1979, J.A. Mullaney, C.J. Trippet, Alcohol dependence and phobias: clinical description and relevance, Br. J. Psychiatry, 135 (1979), pp. 565-573

Munjack et al., 1990, D.J. Munjack, P.L. Baltazar, P.B. Bohn, D.D. Cabe, A.A. Appleton, Clonazepam in the treatment of social phobias: a pilot study, J. Clin. Psychiatry, 51 (Suppl. 5) (1990), pp. 35-40

Noyes et al., 1997, R. Noyes Jr., G. Moroz, J.R. Davidson, M.R. Liebowitz, A. Davidson, J. Siegel, J. Bell, J.W. Cain, S.M. Curlik, T.A. Kent, R.B. Lydiard, A.G. Mallinger, M.H. Pollack, M. Rapaport, S.A. Rasmussen, D. Hedges, E. Schweizer, E.H. Uhlenhuth, Moclobemide in social phobia: a controlled dose-response trial, J. Clin. Psychopharmacol., 17 (1997), pp. 247-254

Nutt and Montgomery, 1996, D. Nutt, S.A. Montgomery, Moclobemide in the treatment of social phobia, Int. Clin. Psychopharmacol., 11 (1996), pp. 77-82

Ontiveros and Fontaine, 1990, A. Ontiveros, R. Fontaine, Social phobia and clonazepam, Can. J. Psychiatry, 35 (1990), pp. 439-441

Papp et al., 1988, L.A. Papp, J.M. Gorman, M.R. Liebowitz, A.J. Fyer, B.S. Cohen, D.F. Klein, Epinephrine infusions in patients with social phobia, Am. J. Psychiatry, 145 (6) (1988), pp. 733-736

Papp et al., 1993, L.A. Papp, D.F. Klein, F. Schneier, R. Cole, M.R. Liebowitz, E. Hollander, A.J. Fyer, F. Jordan, J.M. Gorman, Diagnostic and substance specificity of carbon-dioxide-induced panic, Am. J. Psychiatry, 150 (1993), pp. 250-257

Phillips and Bruch, 1988, S.D. Phillips, M.A. Bruch, Shyness and dysfunction in career development, J. Counsel. Psychol., 35 (1988), pp. 159-165

Potts et al., 1994, N.L. Potts, J.R. Davidson, K.R. Krishnan, P.M. Doraiswamy, Magnetic resonance imaging in social phobia, Psychiatry Res., 52 (1994), pp. 35-42

Potts et al., 1991,N.L.S. Potts, J.R.T. Davidson, K.R.R. Krishnan, P.M. Doraiswamy, J.C. Ritchie, Levels of urinary free cortisol in social phobia, J. Clin. Psychiatry, 52 (11, Suppl.) (1991), pp. 41-42 
Rapaport and Stein, 1994, M.H. Rapaport, M.B. Stein, Serum interleukin-2 and soluble interleukin-2 receptor levels in generalized social phobia, Anxiety, 1 (1994), pp. 50-53

Regier et al., 1990, D.A. Regier, W.E. Narrow, D.S. Rae, The epidemiology of anxiety disorders: The Epidemiologic Catchment Area (ECA) experience, J. Psychiatr. Res., 24 (Suppl. 2) (1990), pp. 3-14

Reich et al., 1988, J. Reich, R. Noyes, W. Yates, Anxiety symptoms distinguishing social phobia from panic and generalized anxiety disorders, J. Nerv. Ment. Dis., 176 (1988), pp. 510-513

Reich et al., 1989, J. Reich, R. Noyes Jr., W. Yates, Alprazolam treatment in avoidant personality traits in social phobic patients, J. Clin. Psychiatry, 50 (1989), pp. 91-95

Reiter et al., 1990, S.R. Reiter, M.H. Pollack, J.F. Rosenbaum, L.S. Cohen, Clonazepam for the treatment of social phobia, J. Clin. Psychiatry, 51 (1990), pp. 470-472

Robins et al., 1981a, L.N. Robins, J.E. Helzer, R. Crougham, J.B. Williams, R.L. Spitzer, $\quad$ NIMH Diagnostic Interview Schedule: Version IIINational Institute of Mental Health, Rockville, MD (1981)

Robins et al., 1981b, L.N. Robins, J.E. Helzer, J. Croughan, K.S. Ratcliff, National Institute of Mental Health Diagnostic Interview Schedule: its history, characteristic and validity, Arch. Gen. Psychiatry, 38 (1981), pp. 381-389

Rosenbaum et al., 1992, J.F. Rosenbaum, J. Biederman, E.A. Bolduc, Comorbidity of parental anxiety disorders as risks for childhood onset in inhibited children, Am. J. Psychiatry, 149 (1992), pp. 475-481

Ross, 1993, J. Ross, Social phobia: the consumer’s perspective, J. Clin. Psychiatry, 54 (Suppl.) (1993), pp. 5-9

Sanderson et al., 1990, W.C. Sanderson, P.A. Di Nardo, R.M. Rapee, D.H. Barlow, Syndrome comorbidity in patients diagnosed with a DSM-III-R anxiety disorder, J. Abnorm. Psychol., 99 (1990), pp. 308-312

Schneier et al., 1992a, F.R. Schneier, J. Johnson, C.D. Hornig, M.R. Liebowitz, M.M. Weissman, Social phobia. Comorbidity and morbidity in an epidemiologic sample, Arch. Gen. Psychiatry, 49 (4) (1992), pp. 282-288

Schneier et al., 1992b, F.R. Schneier, S.J. Chin, E. Hollander, M.R. Liebowitz, Fluoxetine in social phobia, J. Clin. Psychopharmacol., 12 (1) (1992), pp. 62-64

Schneier et al., 1992c, F.R. Schneier, H.R. Juster, R.G. Heimberg et al., Diagnosis and treatment of social phobia, J Pract Psychiatry Behav Health, 2 (1992), pp. 94-104

Schneier et al., 1993, F.R. Schneier, B.S. Jihad, R. Campeas, B.A. Fallon, E. Hollander, J. Coplan, M.R. Liebowitz, Buspirone in social phobia, J. Clin. Psychopharmacol., 13 (1993), pp. 251-256

Schneier et al., 1994, F.R. Schneier, L.R. Heckelman, R. Garfinkel, R. Campeas, B.A. Fallon, A. Gitow, L. Street, D. Del Bene, M.R. Liebowitz, Functional impairment in social phobia, J. Clin. Psychiatry, 55 (8) (1994), pp. 322-331

Schneier, 1995, F.R. Schneier, Clinical assessment strategies for social phobia, Psychiatr. Ann., 25 (1995), pp. 550-553

Schneier et al., 1998, F.R. Schneier, D. Goetz, R. Campeas, B. Fallon, R. Marshall, M.R. Liebowitz, Placebocontrolled trial of moclobemide in social phobia, Br. J. Psychiatry, 172 (1998), pp. 70-77

Slaap et al., 1996, B.R. Slaap, I.M. van Vliet, H.G.M. Westenberg, J.A. Den Boer, Responders and nonresponders to drug treatment in social phobia: differences at baseline and prediction of response, J. Affect. Disord., 39 (1996), pp. 13-19

Solyom et al., 1986, L. Solyom, B. Ledwidge, C. Solyom, Delineating social phobia, Br. J. Psychiatry, 149 (1986), pp. 464-470 
Stein et al., 1992, M.B. Stein, M.E. Tancer, T.W. Uhde, Heart rate and plasma norepinephrine responsivity to orthostatic challenge in anxiety disorders; comparison of patients with panic disorder and social phobia and normal control subjects, Arch. Gen. Psychiatry, 49 (1992), pp. 311-317

Stein et al., 1994, M.B. Stein, J.R. Walker, D.R. Forde, Setting diagnostic thresholds for social phobia: consideration from a community survey of social anxiety, Am. J. Psychiatry, 151 (1994), pp. 408-412

Stein et al., 1995, M.B. Stein, S.M. Delaney, M.J. Chartier, C.D. Kroft, A.L. Hazen, [3H]paroxetine binding to platelets of patients with social phobia: comparison to patients with panic disorder and healthy volunteers, Biol. Psychiatry, 37 (1995), pp. 224-228

Stein et al., 1996a, M.B. Stein, M.J. Chartier, A.L. Hazen, C.D. Kroft, R.A. Chale, D. Cote, J.R. Walker, Paroxetine in the treatment of generalized social phobia: open-label treatment and double-blind placebocontrolled discontinuation, J. Clin. Psychopharmacol., 16 (1996), pp. 218-222

Stein et al., 1996b, M.B. Stein, H.L. Hauger, K.S. Dhalla, M.J. Chartier, G.J. Asmundson, Plasma neuropeptide $\mathrm{Y}$ in anxiety disorders: findings in panic disorder and social phobia, Psychiatry Res., 59 (1996), pp. 183-188

Stein et al., 1998, M.B. Stein, M.R. Liebowitz, R.B. Lydiard, C.D. Pitts, W. Bushnell, I. Gergel, Paroxetine treatment of generalized social phobia (Social Anxiety Disorders): a randomized controlled study, J. Am. Med. Assoc., 280 (1998), pp. 708-713

Tancer et al., 1990, M.E. Tancer, M.B. Stein, C.S. Gelernter, T.W. Uhde, The hypothalamic-pituitary-thyroid axis in social phobia, Am. J. Psychiatry, 147 (1990), pp. 929-933

Tancer et al., 1994, M.E. Tancer, R.B. Mailman, M.B. Stein, G.A. Mason, S.W. Carson, R.N. Golden, Neuroendocrine responsivity to monoaminergic system probes in generalized social phobia, Anxiety, 1 (1994), pp. 216-223

Tiihonen et al., 1997, J. Tiihonen, J. Kuikka, K. Bergstrom, U. Lepola, H. Koponen, E. Leinonen, Dopamine reuptake site densities in patients with social phobia, Am. J. Psychiatry, 154 (1997), pp. 239-242

Turner et al., 1986, S.M. Turner, D.C. Beidel, K.T. Larkin, Situational determinants of social anxiety in clinic and nonclinic samples. Physiological and cognitive correlates, J. Consult. Clin. Psychol., 54 (1986), pp. 523-527

Van Ameringen et al., 1993, M. Van Ameringen, C. Mancini, D.L. Streiner, Fluoxetine efficacy in social phobia, J. Clin. Psychiatry, 54 (1) (1993), pp. 27-32

Van Vliet et al., 1992, I.M. Van Vliet, J.A. den Boer, H.G. Westenberg, Psychopharmacological treatment of social phobia: clinical and biochemical effects of brofaromine, a selective MAO-A inhibitor, Eur.

Neuropsychopharmacol., 2 (1992), pp. 21-29

Van Vliet et al., 1994, I.M. Van Vliet, J.A. den Boer, H.G. Westenberg, Psychopharmacological treatment of social phobia; a double blind placebo controlled study with fluvoxamine, Psychopharmacology, 115 (1994), pp. 128-134

Van Vliet et al., 1997a, I.M. Van Vliet, H.G.M. Westenberg, B.R. Slaap, J.A. den Boer, K.L. Ho Pian, Anxiogenic effects of pentagastrin in patients with social phobia and healthy controls, Biol. Psychiatry, 42 (1997), pp. 76-78

Van Vliet et al., 1997b, I.M. Van Vliet, J.A. den Boer, H.G. Westenberg, K.L. Pian, Clinical effects of buspirone in social phobia: a double-blind placebo-controlled study, J. Clin. Psychiatry, 58 (1997), pp. 164-168

Versiani et al., 1988, M. Versiani, F.D. Mundim, A.E. Nardi, M.R. Liebowitz, Tranylcypromine in social phobia, J. Clin. Psychopharmacol., 8 (1988), pp. 279-283 
Versiani et al., 1992, M. Versiani, A.E. Nardi, F.D. Mundim, A.B. Alves, M.R. Liebowitz, R. Amrein, Pharmacotherapy of social phobia; a controlled study with moclobemide and phenelzine, Br. J. Psychiatry, 161 (1992), pp. 353-360

Versiani et al., 1996, M. Versiani, A.E. Nardi, F.D. Mundim, S. Pinto, E. Saboya, R. Kovacs, The long-term treatment of social phobia with moclobemide, Int. Clin. Psychopharmacol., 11 (Suppl. 3) (1996), pp. 83-88

Versiani et al., 1997, M. Versiani, R. Amrein, S.A. Montgomery, Social phobia — long-term treatment outcome and prediction of response — a moclobemide study, Int. Clin. Psychopharmacol., 12 (5) (1997), pp. 239-254

Wacker et al., 1992, H.R. Wacker, R. Müllejans, K.H. Klein, R. Battegay, Identification of cases of anxiety disorders and affective disorders in the community according to ICD-10 and DSM-III-R by using the Composite International Diagnostic Interview (CIDI), Int. J. Methods Psychiatr. Res., 2 (2) (1992), pp. 91-100

Walker and Stein, 1995, J.R. Walker, M.B. Stein, Epidemiology, M.B. Stein (Ed.), Social Phobia. Clinical and Research Perspectives, American Psychiatric Press (1995), pp. 43-75

Weiller et al., 1996, E. Weiller, J.C. Bisserbe, P. Boyer, J.P. Lépine, Y. Lecrubier, Social phobia in general health care. An unrecognised undertreated disabling disorder, Br. J. Psychiatry, 168 (1996), pp. 169-174

Wells et al., 1989, J.E. Wells, J.A. Bushnell, A.R. Hornblow, Christchurch psychiatric epidemiology study. I. Methodology and lifetime prevalence for specific mental disorders, Aust. NZ J. Psychiatry, 23 (1989), pp. 315326

Wittchen et al., 1992, H.-U. Wittchen, C.A. Essau, D. Zerssen, C.J. von Krieg, M. Zaudig, Lifetime and sixmonth prevalence of mental disorders in the Munich Follow-up Study, Eur. Arch. Psychiatry Clin. Neurosci., 241 (1992), pp. 247-258

Wittchen and Beloch, 1996, H.-U. Wittchen, E. Beloch, The impact of social phobia on quality of life, Int. Clin. Psychopharmacol., 11 (1996), pp. 15-24

Wittchen et al., 1996, H.-U. Wittchen, S. Zhao, J.M. Abelson, J.L. Abelson, R.C. Kessler, Reliability and procedural validity of UM-CIDI DSM-III-R phobic disorders, Psychol. Med., 26 (6) (1996), pp. 1169-1177

Wittchen et al., 1998, H.-U. Wittchen, C.B. Nelson, G. Lachner, Prevalence of mental disorders and psychological impairments in adolescents and young adults, Psychol. Med., 28 (1998), pp. 109-126

World Health Organization, 1990, World Health Organization, Composite International Diagnostic Interview (CIDI) World Health Organization, Division of Mental Health, Geneva (1990) 